
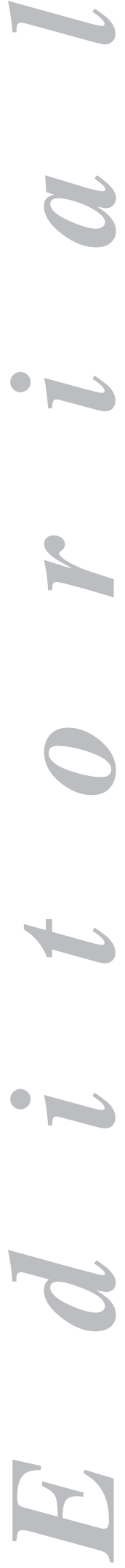

\section{Crohn's disease, feeling well or healthy?}

Crohn's disease, as ulcerative colitis, is an immunoinflammatory condition that, because of its features, including chronicity, common incidence in younger subjects, complications, need for continued therapy with potential adverse events, need for surgical procedures, etc., has a profound impact on the health of involved patients. This implies that Crohn's disease may now be considered a disabling condition (1) in terms of its physical, occupational (2), financial (3), and psychological (4) effects, which results in a marked impairment of health-related quality of life in people (5). Various factors related to the effects on quality of life in individuals with Crohn's disease have been described, but most important is the presence of active disease or flare-ups (6). Therefore, a basic goal of therapy is symptom control and the restoration of quality of life, and measuring patient quality of life is thus an endpoint in all modern clinical trials on Crohn's disease. Therapy, whether with drugs or surgery, is known to be effective (7) and improves patient quality of life. Furthermore, the beneficial effect of treatment on perceived health seems to last long term for as long as therapy's effects persist, whether immunomodulator (8) or anti-TNF $\alpha$ $(9,10)$.

Currently, given the introduction of new drugs, including immunomodulators and anti-TNF $\alpha$ biologicals, the management of patients with Crohn's disease is given not only for symptom remission or flare-up and complications prevention but also mucosal healing. The mucosal healing concept, recently introduced for the management of patients, basically refers to lesion clearance on colonoscopy or a minimal rating for the endoscopic activity indices used during colonoscopy. It has been seemingly confirmed that the achievement of mucosal healing in Crohn's disease modifies this condition's natural history by improving its clinical course, reducing corticoid requirements, and preventing complications $(11,12)$. However, it must be remembered that lesion healing is not necessarily the only goal when caring for patients with Crohn's disease since health recovery is equally important. In this respect, while many "objective" methods exist for the assessment of patients with Crohn's disease (13), none of them may replace the perceptions of patients as active subjects involved in their own care when attempting to establish their health status. It is not so much about initiating a discussion on whether symptoms or lesions should be treated (14) but about considering the relevance that patients with Crohn's disease may recognize their own health status, expressed and quantified in terms of quality of life. Bearing such considerations in mind, the goal of caring for these patients is not only symptom control and lesion healing but also a restoration of their quality of life.

The quality of life concept is not always related to Crohn's disease activity given its subjective nature. No wonder then that symptom remission is not synonymous 
with good quality of life since these two measures differ. Therefore, given the subjectivity of quality of life and the fact that its restoration is a therapeutic goal together with remission achievement and maintenance, awareness is important on the status of quality of life for patients with inactive Crohn's disease.

In the present issue of this Journal, Dr. Iglesias and coworkers (15) present a highly relevant paper for the recognition of quality of life in patients with Crohn's disease in remission. A group of 92 patients in long-term remission for over 6 months were administered a specific quality-of-life measurement questionnaire (36item IBDQ) and a widely used general questionnaire (SF-36). The joint administration of both questionnaires allowed authors to establish patient quality of life extent, to determine factors involved therein, and to compare it to values prespecified for the Spanish population. Despite the fact that patients were both clinically (as per CDAI and Harvey's index) and biologically (as per CRP) in stable remission, the standardized rating of all SF-36 dimensions never reached the general population's standard adjusted for age and sex, which represents a worse quality of life in patients as compared to the general population. Furthermore, the dimension that obtained a poorer rating by patients was perceived overall health. Such data confirm that keeping the disease under clinical and biological control cannot adequately restore perceived normal health and, as the authors state, patients with Crohn's disease should also be cared for during remission. Not all studies accurately replicate these results, which may be accounted for by methodological (case-control studies vs. comparisons to standard values available for the general population) or population-related (patients requiring therapy with biologicals or otherwise) aspects.

To conclude, even when Crohn's disease is clinically and biologically in remission, and possibly despite mucosal healing, patients may report a poorer quality of life as compared to that perceived by healthy individuals. Therefore, the goal of health care for these patients should be more ambitious and never focus exclusively on the management of symptoms, biological markers, and endoscopic lesions, but also on the restoration of quality of life so that patients may perceive that their health status has fully recovered.

F. Casellas

Unitat d'Atenció Crohn-Colitis. Hospital Universitari Vall d'Hebron. Ciberehd. Barcelona, Spain

\section{REFERENCES}

1. Peyrin-Biroulet L, Loftus EV Jr, Colombel JF, Sandborn WJ. The natural history of adult Crohn's disease in population-based cohorts. Am J Gastroenterol. 2010; 105: 289-97.

2. Vergara M, Montserrat A, Casellas F, Maudsley M, Gallardo O, Ricart E, et al. Validation of the Spanish Work Productivity and Activity Impairment questionnaire: Crohn's disease version. Eur J Gastroenterol Hepatol 2009; 21: 809-15.

3. Juan J, Estiarte R, Colome E, Artes M, Jimenez FJ, Alonso J. Burden of illness of Crohn's disease in Spain. Dig Liver Dis 2003; 35(12): 853-61.

4. Iglesias M, Barreiro de Acosta M, Vázquez I, Figueiras A, Nieto L, Lorenzo A, et al. Psychological impact of Crohn's disease on patients in remission: anxiety and depression risks. Rev Esp Enferm Dig 2009; 101: 24957.

5. Casellas F, Arenas JI, Baudet JS, Fabregas S, Garcia N, Gelabert J, et al. Impairment of health-related quality of life in patients with inflammatory bowel disease: a Spanish multicenter study. Inflamm Bowel Dis 2005 11: 488-96. 
6. Casellas F, Alcalá MJ, Prieto L, Armengol JR, Malagelada JR. Assessment of the influence of disease activity on the quality of life of patients with inflammatory bowel disease using a short questionnaire. Am J Gastroenterol 2004; 99: 457-61.

7. Casellas F, López Vivancos J, Badia X, Vilaseca J, Malagelada JR. Impact of surgery for Crohn's disease on health-related quality of life. Am J Gastroenterol 2000; 95: 177-82.

8. Calvet X, Gallardo O, Coronas R, Casellas F, Montserrat A, Torrejón A, et al. Remission on thiopurinic immunomodulators normalizes quality of life and psychological status in patients with Crohn's disease. Inflamm Bowel Dis 2006; 12: 692-6.

9. Casellas F, Rodrigo L, Niño P, Pantiga C, Riestra S, Malagelada JR. Sustained improvement of health-related quality of life in Crohn's disease patients treated with infliximab and azathioprine for 4 years. Inflamm Bowel Dis 2007; 13: 1395-400.

10. Panaccione R, Colombel JF, Sandborn WJ, Rutgeerts P, D'Haens GR, Robinson AM, et al. Adalimumab sustains clinical remission and overall clinical benefit after 2 years of therapy for Crohn's disease. Aliment Pharmacol Ther. 2010 Mar 18. [Epub ahead of print]

11. Baert F, Moortgat L, Van Assche G, Caenepeel P, Vergauwe P, De Vos M, et al.; Belgian Inflammatory Bowel Disease Research Group; North-Holland Gut Club. Mucosal healing predicts sustained clinical remission in patients with early-stage Crohn's disease. Gastroenterology 2010; 138: 463-8.

12. Frøslie KF, Jahnsen J, Moum BA, Vatn MH; IBSEN Group. Mucosal healing in inflammatory bowel disease: results from a Norwegian population-based cohort. Gastroenterology 2007; 133: 412-22.

13. Loftus EV Jr. Clinical perspectives in Crohn's disease. Objective measures of disease activity: alternatives to symptom indices. Rev Gastroenterol Disord 2007; 7(Supl 2): S8-S16.

14. Schölmerich J. Review article: should we treat symptoms or lesions in Crohn's disease? The case for treating symptoms. Aliment Pharmacol Ther. 2006; 24(Suppl 3): 33-6.

15. Iglesias M, Vázquez I, Barreiro-de Acosta M, Figueiras A, Nieto L, Piñeiro M, et al. Calidad de Vida en pacientes con Enfermedad de Crohn en remisión. Rev Esp Enferm Dig 2010; 11: 